\title{
العادات الغذائية لطلاب المرحلة الثانوية بمملكة البحرين، \\ وجمهورية مصر العربية. (الأضرار والحلول)
}

د// عزت احمد محمد الفضالي

أستاذ مساعد الكيمياء الفيزيائية- قسم تقوبم

الموارد الطبيعية والتخطيط - جامعة مدينة

السادات
أ.د/ يحيى عبد المنعم عبد الهادي

أستاذ التغذية وعلوم الأطعمة - كلية التربية النوعية

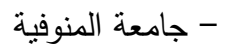

\section{أيمن صلاح عبد المطلب البنا}

طالب دراسات عليا

الملخص

هدفت الدراسة الى مقارنة بين العادات الغذائية لطلاب المرحلة الثانوبة بمملكة البحرين والعادات الغذائية لطلاب المرحلة نفسها بجمهورية مصر العربية،وذلك للتعرف على العوامل التي تؤثز في العادات الغذائية لعينة الدراسة، ولتحقيق ذلك اعتمدت الدراسة على المنهج الوصفي التحليلي ومجموعة من الاستبانات تم تطبيقها على . . 1 طالب بالمرحلة الثانوبة بمملكة البحرين و . 1 طالب بجمهورية مصر العربية، وقد توصلت الدراسة إلى النتائج الآتية: فقد بينت الدراسة أن · ب\% من عينة الطلاب البحرينيين لا يتتاولون الفطور، وأرجع نصفهم السبب في ذلك إلى عدم وجود الوقت، وبرر 0\% عدم تتاول وجبة الفطور بعدم وجود الثهية والرغبة في تتاوله، أما الطلاب المصريون فإن هذه العادة غير منتشرة بينهم بشكل كبير، فقد بلغت نسبة من لا يتناول وجبة الفطور منهم ؟\% فقط. يظهر جليا انتشار عادة تتاول الحلويات بين الوجبات في صفوف طلاب العينيتين، فقد بلغت نسبة من يعتاد من الطلاب البحرينيين تتاول الحلويات بين الوجبات . ج\%، وبلغت جه\% في عينة الطلاب المصريين،. كثفت الدراسة الحالية أن نسبة كبيرة من الطلاب تفضل إضافة كمية زائدة من السكر إلى المشروبات، فنسبة هo \% من عينة الطلبة المصربين تفضل إضافة ثلاث ملاعق للمشروبات، و ع ا \% منهم يفضلون إضافة أكثر من ثلاث ملاعق، أما الطلبة البحرينيون فإن ^ء \% منهم يفضلون إضافة ثلاث ملاعق للمشروبات، و 1 1 \% يضيفون أكثر من ذلك. فقد كثفت الدراسة الحالية أن ع ؟ \% من عينة الطلاب البحرينيين يتتاولون المشروبات الغازية بشكل يومي، في حين انخفضت هذه النسبة إلى النصف في عينة الطلاب المصريين حيث 
بلغت rr \% \% أما الذين يشربونها أحيانا فنسبتهم مرتفعة في عينة الطلبة المصرين حيث بلغت

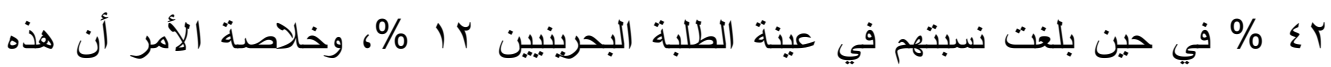
النسب تدل بشكل واضح على انتشار هذه العادة في صفوف الطلبة، والتي لها أضرار خطيرة على صحتهم. كثفت الدراسة الحالية أن VY V \% من عينة الطلبة البحرينيين يتتاولون الطعام

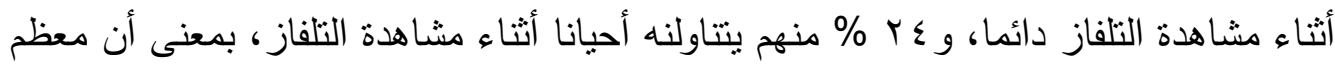
الطلبة البحرينيين بتتاولون وجباتهم الغذائية أمام شاثنة التلفاز ، أما في عينة الطلبة المصريبين فإن النتيجة كانت على النصف من نتيجة عينة الطلبة البحرينيين، فقد كثفت الدراسة أن نسبة

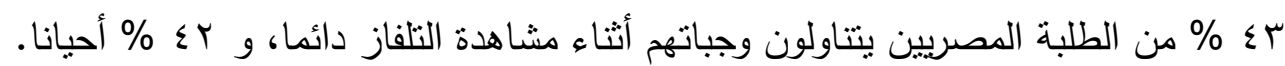
وعموما فالمسألة تعتبر ظاهرة في صفوف الطلبة، وقد أثثتت الدراسة خطورة هذا الأمر

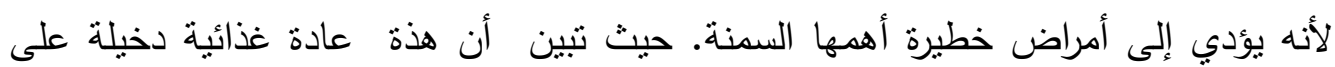

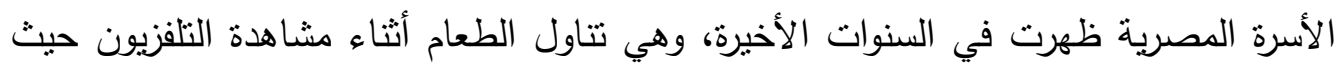
يترتب على ذلك تتاول كميات كبيرة من الطعام بدون وعي، حيث لا يشعر الفرد بالثبع، مما

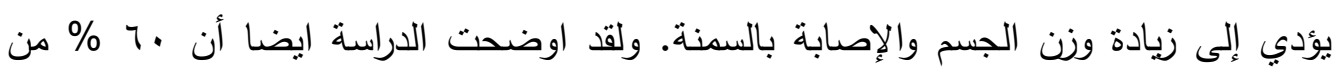
عينة الطلاب البحرينيين يتتاولون البطاطس المقلية بشكل يومي بين الوجبات الرئيسية، و ^

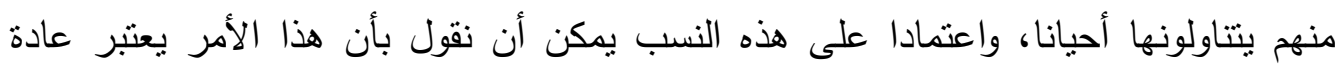

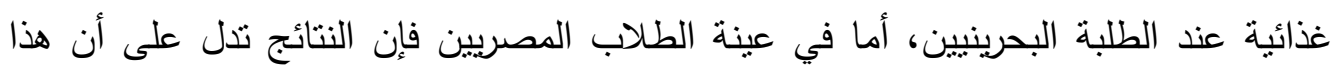

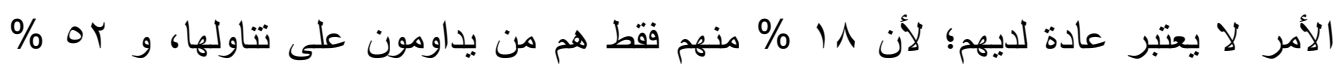

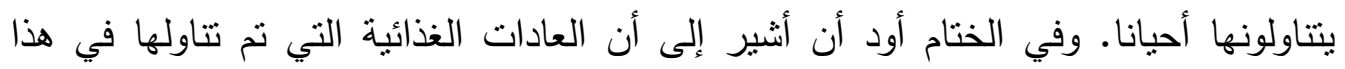
البحث ليست هي العادات الغذائية المنتشرة بين أفراد عينتي البحث ومن يعيش في محيطهم إنى فقط، بل هناك عادات غذائية أخرى، فهي كثيرة ومتتوعة وتتطور مع تطور المجتمع وتغير

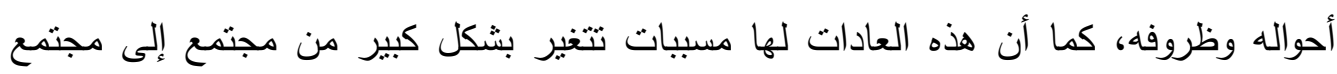

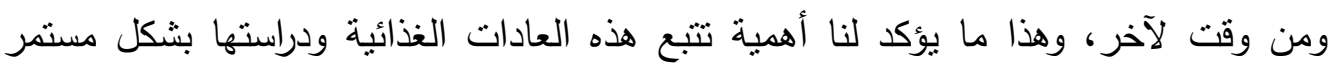
وتقديم الحلول والاقتراحات المناسبة لعلاجها. 


\section{Comparative study of the factors affecting the food habits among school students in the secondary stage in the Kingdom of Bahrain and Arab Republic of Egypt}

\section{Abstract}

In this study, the researcher made a comparative study of eating habits between secondary stage students in each of Bahrin Kingdom and The Arab Republic of Egypt's schools .

To find out the factors affecting eating habits for the chosen sample of study depending on the analytic and descriptive method of study, furthermore a survey of people's eating habits applied for 100 students in each country.

The study abstracted that $20 \%$ of Bahrinian students' sample don't have breakfast. Half of them justified that as they have no time. However, $5 \%$ of them returned that back to loss of appetite and absence of desire for eating. On the other hand the habit of neglecting breakfast was uncommon for the Egyptian students somewhat, as the percentage of students who don't have breakfast reached just $4 \%$ of the sample. The habit of eating sweets between meals appears clearly through the students of both samples. Percentage of Bahrinian students who have this habit is $60 \%$ while it was $56 \%$ of Egyptian students' sample. The exist study reveals that a high percentage of students prefer adding excessive amount of sugar to drinks. $58 \%$ of Egyptian students' sample prefer adding three spoons of sugar to their drinks furthermore $14 \%$ of them do more that they add more than three spoons of sugar to their drinks. According to Bahrinian students, the study indicates that $48 \%$ of them prefer adding three spoons of sugar to their drinks while $156 \%$ add more than three.

The study revealed that $64 \%$ of Bahrinian students' sample have soda pop daily. On the other hand this percentage decreased to half of it in Egyptian students' sample, as it reached 32\%. For those who occasionally have soda pop, the percentage increased in Egyptian students to $42 \%$ of them as compared with $\%$ ) rof Bahrinian students.

Finally we concluded that the mentioned habit is clearly common among the students and in turn it will affect badly on their health. As indicated by study $72 \%$ of Bahrinian students' sample always eat food during watching TV in addition $24 \%$ of them sometimes eat food while watching TV. This means that the majority of students have foods while watching TV. According to Egyptian student' sample, the result was at 
the half way comparing with Bahrinians. The study concluded that $43 \%$ of Egyptian students always have their meals while watching TV and $42 \%$ of them sometimes do that. Generally the phenomena is common among the students. The study proved the severity of this case as it causes several dangerous diseases such as obesity. It is true that eating foods while watching TV is a bad habit acquired recently by Egyptian families. This resulted in eating large amount of foods incorrectly without caring so one can not satisfied and in turn this leads to weight gaining and obesity occurs as a result of that.

The study indicated that $60 \%$ of Bahrinian students' sample eat French fries daily between meals and $8 \%$ of them do that occasionally. Depending on this percentages we can say that the matter may be considered as a habit among Bahrinian students while according to Egyptian students it can not be considered as a habit as $18 \%$ of them do that and $52 \%$ of them sometimes do.

Finally I'd like to pay attention that eating habits discussed in this study are not the only eating habits common among the members of both samples of study or their surrounded communities, but there are many other various habits differ and develop according to the community development and its changed conditions.

In addition to that, all these habits have many reasons that vary from one community to other at different times. This highlights the significance of continuous detailed study of these eating habits and discussing its reasons and offering the suggested convenient solutions of it to be realized and in turn to be treated 


\section{أولا : المقدمة :}

يلعب الغذاء دوراً هاماً في حياة الأمم والثعوب حيث أن الحالة الغذائية تمنل مرآة تتعكس

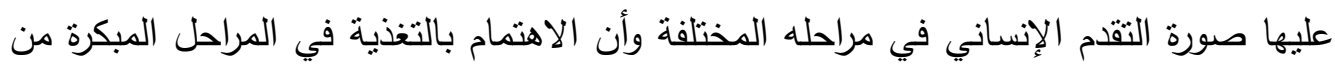
العمر يقلل من فرصة تعرضه للإصابة بأمراض سوء التغذية وبذلك يمكنه النمو والنطور وفقاً

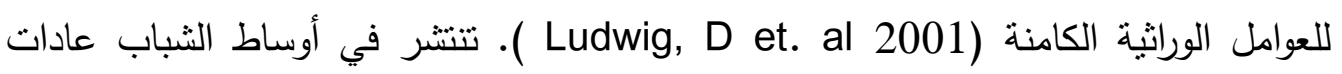
غذائية كثيرة، بعضها جيد، وبعضها اللآخر سيء كتتاول وجبة الفطور في البيت، وتتاول المشروبات الغازية بشكل يومي، وتتاول الوجبات السريعة كالهمبورجر والدجاج المقلي والبيتزا والبطاطس المقلية والسجق، وتتاول عدد كبير من الثباب للمشروبات الرياضية مشروبات الطاقة، وكل هذه العادات لها عوامل ساهمت في تكونها لادى الثباب وانتشارها بينهم، وفي هذا لهن

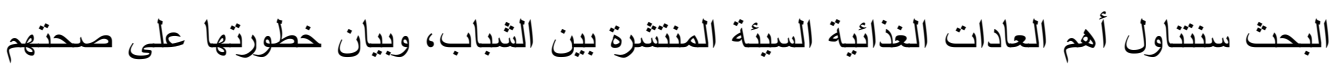
في الحاضر ومستقبلا، والكثف عن العوامل المساعدة في تكون هذه العادات وانتشارها في أوساط الثباب عامة، وبين الطلاب خاصة.

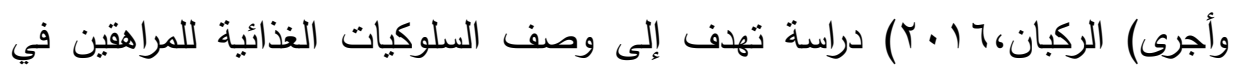
مدينة الرياض، ودراسة العوامل المختلفة المؤثرة فيها. كما هدفت الدراسة إلى تقييم معلومات المراهقين عن التغذية وعلاقة تلك المعرفة بسلوكهم الغذائي. وكانت الدراسة مسحية مقطعية شملت المراهقين في مدينة الرياض من السعوديين وغير السعوديين. وتم اختيار العينة بطريقة

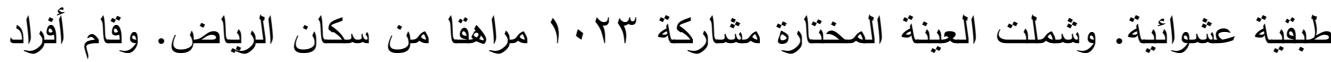

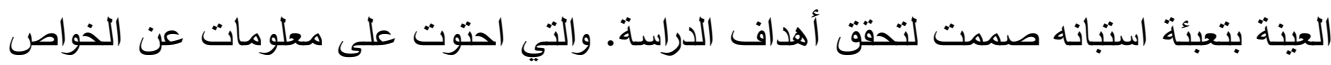

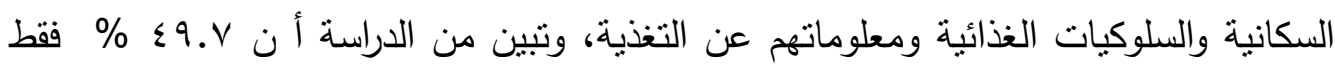
منهم يتتاولون الإفطار يوميا في المنزل، وان م, بr \% يتتاولون المشروبات الغازية بصورة

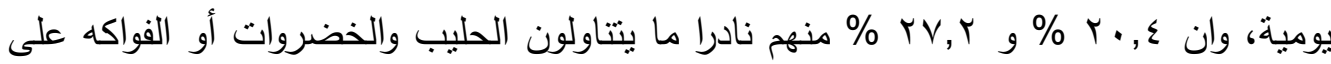
التوالي. كما أنضح وجود علاقة عكسية بين العمر وكل من تتاول الإفطار يوميا في المنزل وتتاول الحليب ومشتقاته وتتاول الخضروات والفواكه وان هناك علاقة طردية بين العمر وتتاول

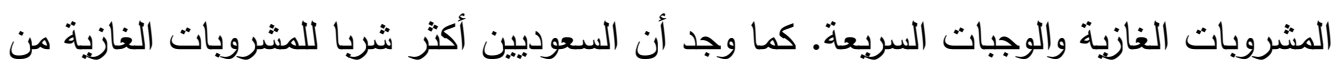

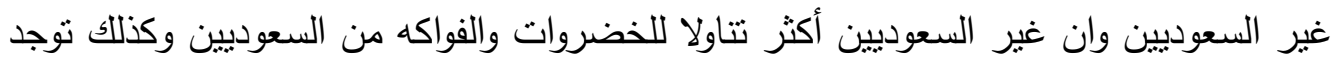
علاقة طردية بين وجود الأمراض المزمنة وبعض السلوكيات غير الصحية، ككثرة شرب لهربين المشروبات الغازية وتتاول الوجبات السريعة وقلة شرب الحليب ومشتقاته وتتاول الخضروات 
والفواكه كما أن المدخنين أقل حرصا على تتاول الإفطار الصباحي وتتاول الحليب والخضروات والفواكه من غير المدخنين، وكل ذلك بدلالة إحصائية ذات فروق معنوية.ووجدت كذلك علاقة طردية بين صحة المعلومات الغذائية والممارسات الغذائية المختلفة. وأن كثيرا من المراهقين يعتمدون على وسائل الإعلام العامة التلفاز والراديو والصحف والمجلات) في معلوماتهم الغذائية. وتوصلت النتائج إلى أن السلوك الغذائي للمراهقين في السعودية يحتاج إلى مزيد عناية

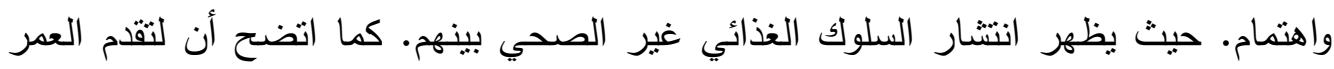
وللتنخين ولضعف المعلومة الغذائية أثرا في ذلك. ومن هنا فإننا نحتاج إلى ترشيد وسائل الأعلام لخدمة التوعية الغذائية للمجتمع من خلال البرامج الإرشادية والعناية بالإعلانات التجارية وبرامج الأطفال والثباب، مع أهمية التركيز على تفعيل دور الأسرة والمدرسة. وقداته أثنتت الدراسات والبحوث العلمية أن الصحة والتغذية السليمة ليست مسئولة فقط عن تكوين الئن وبناء الجسم ولكنهما يلعبان دورا مهماً في توجيه السلوك الاجتماعي والأخلاقي والفكري للفرد ودليل مباشر على نوعية الحياة ، ودليل غير مباشر على مدى التطور الاجتماعي والاقتصادي

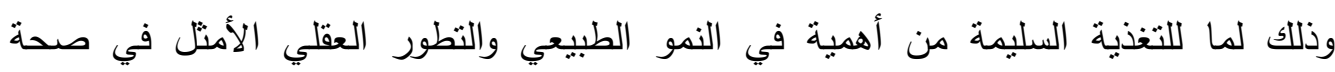
المريض والسليم والحفاظ على صحة جيدة خلال حياة الإنسان • ( آيات الدسوقي ، ؟ . . r) . وتؤكد العديد من الدراسات والبحوث العلمية أن مشكلة سوء التغذية وانتشار الكثير من الأمراض لا ترجع إلى نقص أو زيادة الموارد المالية فقط وإنما ترجع أيضا إلى نقص الثئه الوعي الغذائي

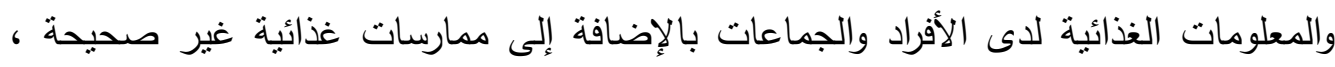

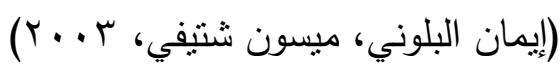

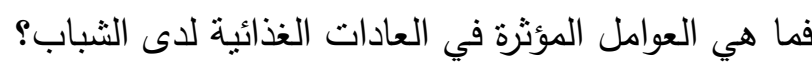
للإجابة عن هذا السؤال تم إجراء دراسة على عينة من طلاب المدارس بمملكة البحرين

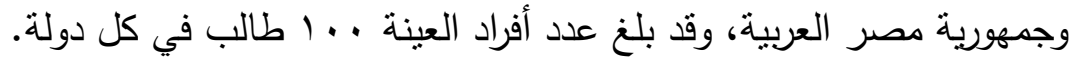

ثانيا : مشكلة البحث :

تتلخص مشكلة البحث بوجود أنماط غذائية متعددة ومختلفة وتتطلع الدارسة إلى دراستها للوصول إلى تقييمها غذائياً وكذلك علاوة على دراسة الأنماط الغذائية لطلاب المدارس فئ ودئ

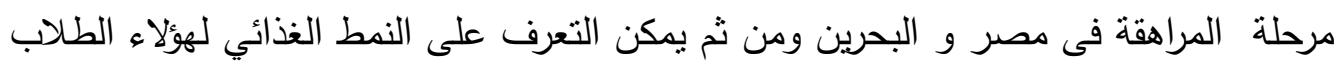
ومعرفة اثر هذه العادات الغذائية على الحالة الغذائية لهم. 


\section{تهاف هذه الاراسة إلى :}

1-دراسة تأثثر بعض العادات والتقاليد على النمط الغذائي للمراهق.

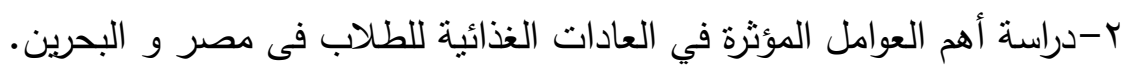

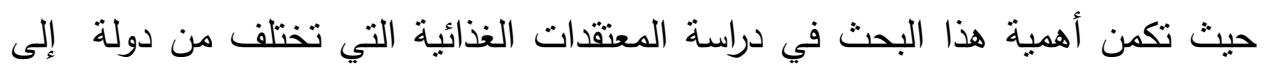

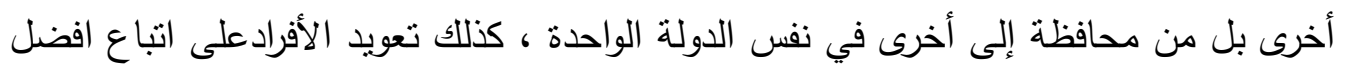

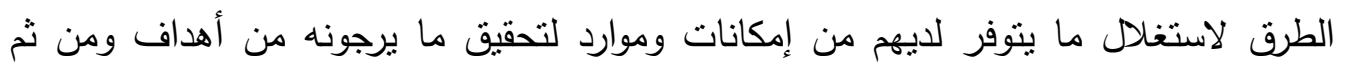

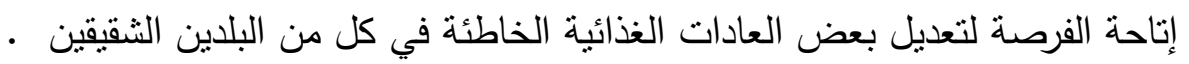
ثالثا : البث : حدود البحث:

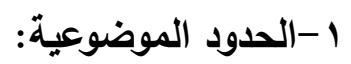

يمكن تحديد الحدود الموضوعية للبحث بحجم العينة المستخدمة وهى عينة من طلاب المرحة الثانوية فى جمهورية مصر العربية، ومملكة البحرين، والبالغ عددهم ( . . ب طالب).

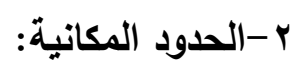

تم إجراء البحث على عينة من الطلاب يقطنون بمحافظة المحرق بمملكة البحرين، ومحافظة المنوفية بجمهورية مصر العربية.

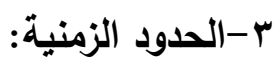
طبقت الأدوات المستخدمة فى هذا البحث على عينة من الطلاب خلال العام الدراسى $\cdot r \cdot 10 / r \cdot 1 \leq$ رابعا : إجراءات المنهجية: 1-المنهج :اتبعت في إنجاز هذا البحث على منهجين هما:

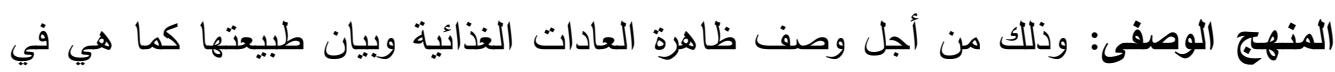
الواقع، وتحديد خصائصها، مع تحويل كل هذه المعلومات إلى وصف رقدمي من خلال أرداد أرقام وجداول توضح مقدار هذه الظاهرة. المنهج التحليلي: وذلك خلال تحليل المعلومات التي تم تجميعها من الاستمارات من أجل التوصل إلى النتائج التي تحتويها، وبعد ذلك لا بد من تفسيرها تفسيرا علميا، واستتباط ما يمكن استتباطه منها. 


\section{مر البحث من مراحل عديدة أهمها:}

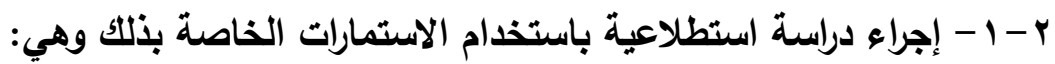
أ- تم إعداد استمارة استطلاع رأي لبعض الطاء الطلاب من العينة (العينة المصغرة).

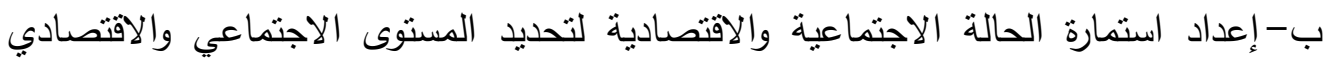
لطلاب العينة .

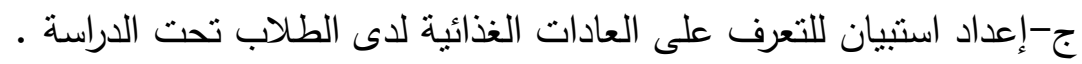

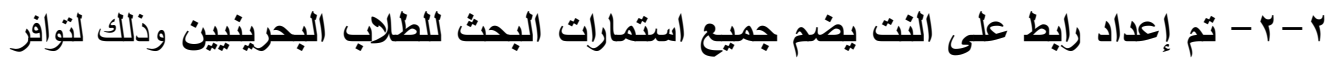

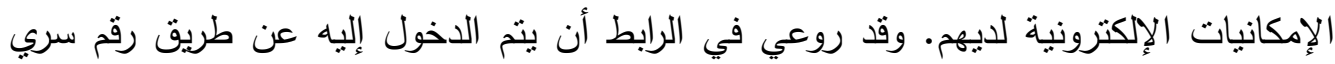

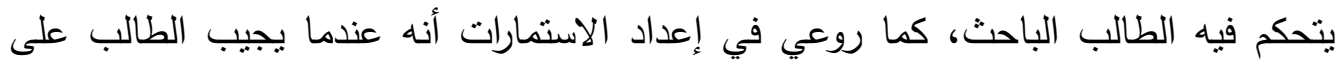

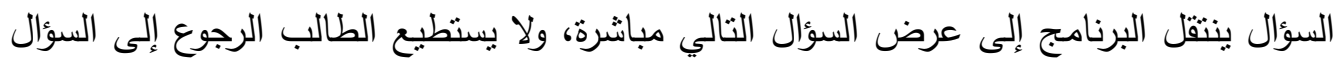

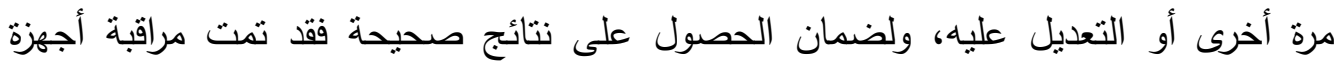

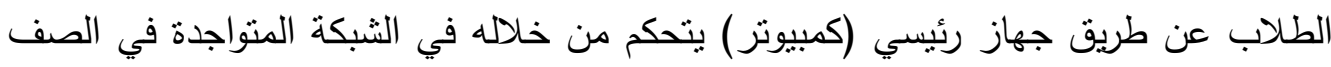

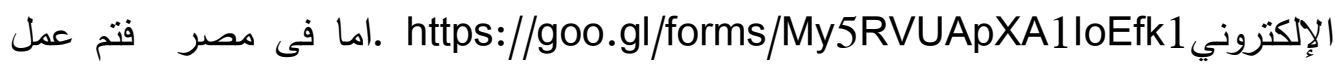
استمارات ورقية نم توزيعها على الطلاب لعدم نوافر الإكانيات.

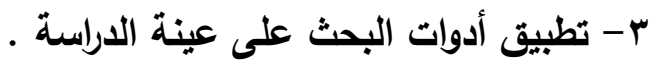

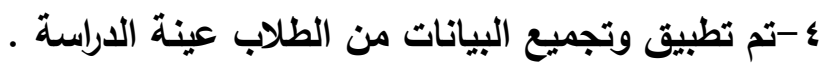

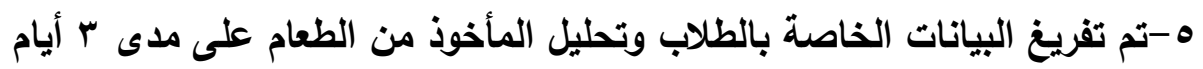

خامسا: الاستمارات الخاصة بالبحث: 1-الاستبيان وخطوات بنائه:

تعتبر الاستبيانات من أكثر الأدوات البحثية التي يمكن للباحثين استخدامها في جمع المعلومات والتعرف على الآراء وقد استخدمت الباحث في الدراسة الحالية الاستبيان باعتباره

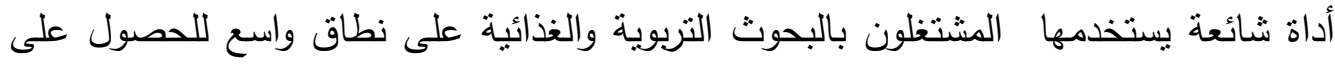

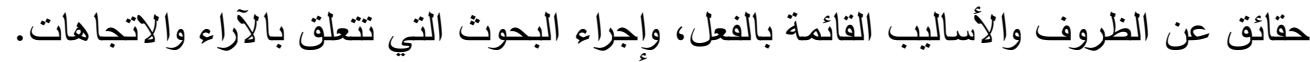

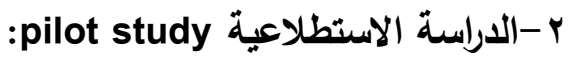

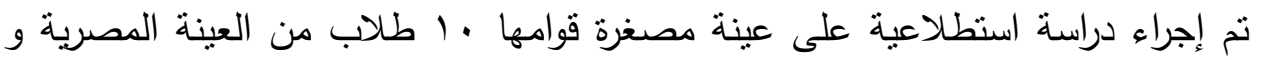
البحرينية. والهدف من هذه الدراسة الاستطلاعية هو التحقق من صياغة الأسئلة وفهمها،

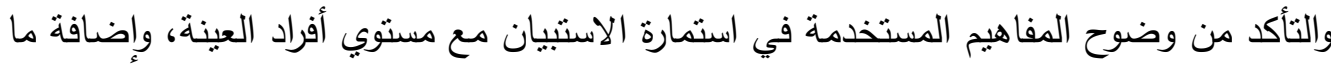

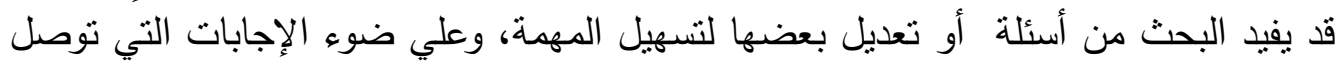

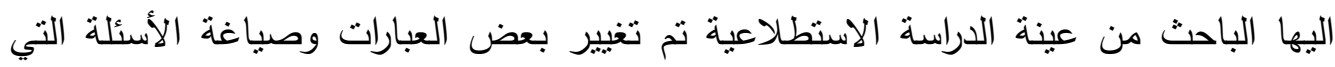
توصل اليها الباحث في صورتها النهائية. 


\section{r-صدق الاستبيانContent Validity:}

حيث عرضت استمارة الاستبيان على لجنة المحكمين وقد أخذت الأسئلة التي بلغت نسبة التبان

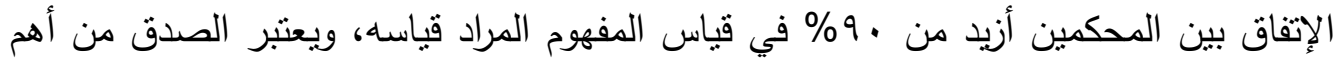

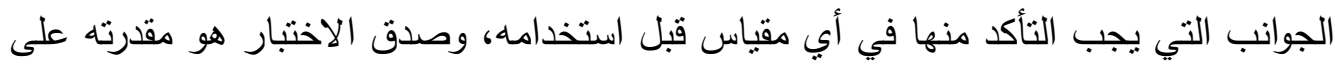

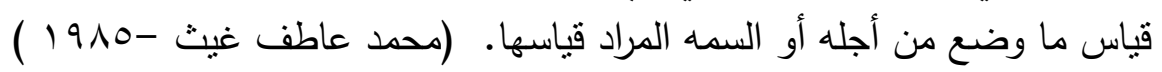
سادسا النتائج : العادات الغذائية المنتشرة بين طلاب المدارس في المراد المبلة الثانوية في مملكة البحرين وجمهورية مصر العربية: لتحديد العادات الغذائية لطلاب المرحلة الثانوية في مملكة البحرين وجمهورية مصر العربية

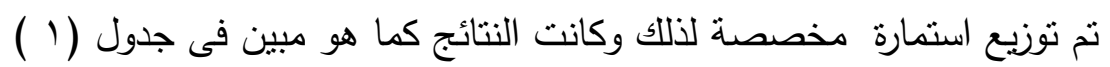
جدول (1): العادات الفذائبة لطلاب المرحلة الثانوية في مملكة البحرين وجمهورية مصر العربية

\begin{tabular}{|c|c|c|c|c|}
\hline \multicolumn{2}{|c|}{ الطلاب البحرينيون } & \multicolumn{2}{|c|}{ الطلاب المصريون } & \multirow{2}{*}{ 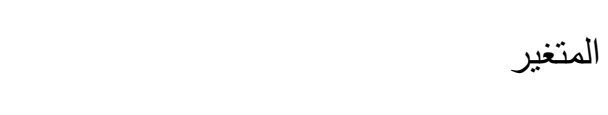 } \\
\hline 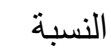 & 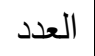 & 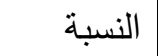 & 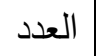 & \\
\hline & & & & 1 - عدد الوجبات: \\
\hline$\% r$ & r & $\%$. & . & ـ ـ واحدة \\
\hline$\% r \leq$ & $r \varepsilon$ & $\% 17$ & 17 & 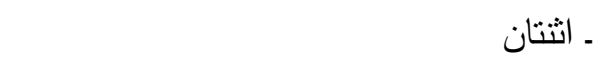 \\
\hline$\%$ ฯ & 71 & $\% \wedge$. & $\wedge$. & ـ ثلاثة \\
\hline$\% 7$ & 7 & $\% \varepsilon$ & $\varepsilon$ & ـ ـ أكثر من ذلك \\
\hline & & & & r - الوجبة المهملة: \\
\hline$\%$ r. & r. & $\%$ ro & $\varepsilon$ & ـ الافطار \\
\hline$\% r$ & r & $\%$ rv.o & 7 & 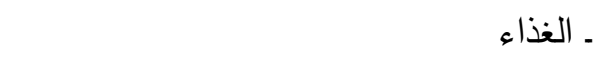 \\
\hline$\% r$ & r & $\%$ rv.o & 7 & 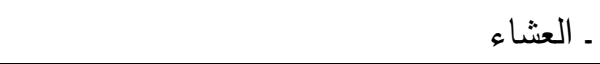 \\
\hline & & & & r- ما السبب في عدم الإفطار؟ \\
\hline$\% 1$. & 1. & $\%$ vo & r & ـ عدم وجود وقت ع ع \\
\hline$\% \circ$ & 0 & $\%$ ro & 1 & ـ عدم وجود شهية \\
\hline$\% \circ$ & o & - & - & ـ ـ أسباب أخرى \\
\hline & & & & ع - ما هي الأطعمة المتناولة بين الوجبات؟ \\
\hline$\%$ ч. & 7. & $\% 04$ & 07 & 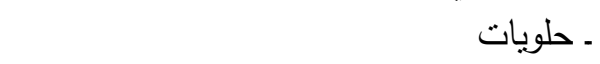 \\
\hline$\% \circ$ & 0 & $\% 1$. & 1. & ـ عصائر \\
\hline$\%$ ro & ro & $\%$ r. & $r$. & ـ ياه غازية \\
\hline$\% \circ$ & 0 & $\% 1$. & 1. & ـ ـ ساندويتشات \\
\hline$\% \circ$ & 0 & $\% \varepsilon$ & $\varepsilon$ & ـ فاكهة \\
\hline$\% r$. & $r$. & $\%$ & Ir & ـ ـ ملعقة ملعقة سكر تضيفها إلى المشرويات؟ \\
\hline
\end{tabular}




\section{العددالثاني عشر أكتوير V V P ج P}

المجلة العلمية لكلية التربية النوعية

\begin{tabular}{|c|c|c|c|c|}
\hline$\% 17$ & 17 & $\%$ rr & rt & ـ ملعقتان \\
\hline$\% \leqslant \wedge$ & $\Sigma \Lambda$ & $\% \circ \wedge$ & $0 \wedge$ & ـ ثلاث ملاعق \\
\hline$\% 17$ & 17 & $\% \backslash \varepsilon$ & $1 \leq$ & ـ أكثر من ذلك \\
\hline & & & & צ- هل تتناول المخلات؟ \\
\hline$\% 17$ & 17 & $\% \leq \varepsilon$ & $\varepsilon \varepsilon$ & ـ نعم \\
\hline$\% 7$. & 7. & $\% \backslash 1$ & 11 & V. \\
\hline$\%$ r $\varepsilon$ & $r \varepsilon$ & $\%$ rᄉ & r人 & 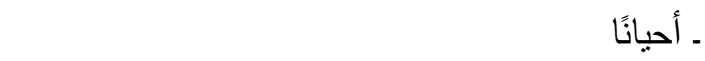 \\
\hline & & & & - هل تناول الشاي بعد الوجبات؟ \\
\hline$\%$ r & $r \varepsilon$ & $\% \leq \wedge$ & $\varepsilon \wedge$ & 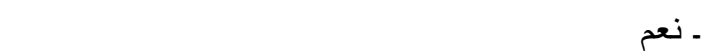 \\
\hline$\% 17$ & 17 & $\%$ ir & ir & $y$ \\
\hline$\%$ ฯ. & 7. & $\% \varepsilon$. & $\varepsilon$. & 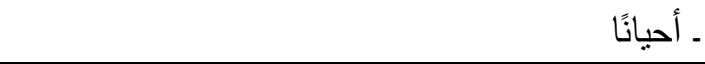 \\
\hline & & & & ^- هل تشرب اللبن؟ \\
\hline$\% 07$ & 07 & $\% \leq \varepsilon$ & $\varepsilon \varepsilon$ & ـ ن نعم \\
\hline$\% 17$ & 17 & $\%$ r & r & $\gamma$. \\
\hline$\%$ r^ & rᄉ & $\%$ r & rT & 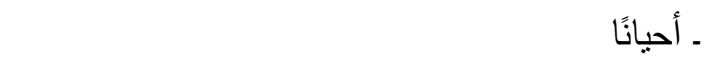 \\
\hline$\%$. & - & $\% 7$ & 7 & ـ ـ هليلة تفضل كمية الملح في الطعام؟ \\
\hline$\% \vee 7$ & VT & $\% 7$. & 7. & 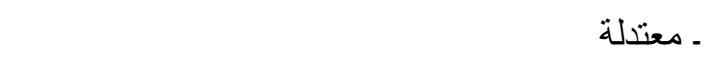 \\
\hline$\% \quad r \varepsilon$ & $r \varepsilon$ & $\%$ r $\varepsilon$ & $r \varepsilon$ & ـ - ملح - ملح \\
\hline$\% 7 \leq$ & $\leqslant 7$ & $\%$ rr & 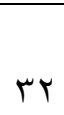 & ـ ـ ـ هل تناول المياه (المشرويات) الغازية؟ \\
\hline$\%$ r & $r \leq$ & $\%$ rA & rA & V. \\
\hline$\%$ Ir & ir & $\% \leq r$ & $\varepsilon r$ & 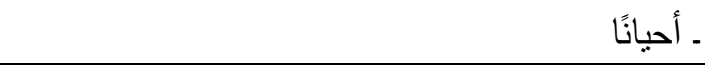 \\
\hline & & & & 1 1 - هل تتناول الطعام أمام التلفزيون؟ \\
\hline$\% \vee r$ & $V Y$ & $\%$ rs & $r \varepsilon$ & ـ ن نعم \\
\hline$\% \leq$ & $\varepsilon$ & $\%$ r & $r \varepsilon$ & $\gamma$ \\
\hline$\%$ r & r & $\% \quad r \leq$ & $\varepsilon r$ & 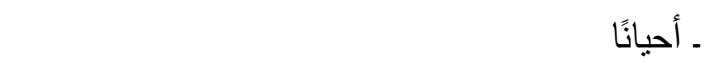 \\
\hline$\% 7$. & 7. & $\% \backslash \wedge$ & 11 & أغذية خفيفة بين الوجبات؟ لت البطاطس الشيبسي باعتبارها \\
\hline$\%$ rr & 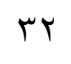 & $\%$ r. & r. & \\
\hline$\% \wedge$ & $\wedge$ & $\%$ or & or & ــ ــ أحيانًا \\
\hline
\end{tabular}


من خلال الجدول السابق يتبين أن أهم العادات الغذائية المنتشرة بين طلاب المرحلة الثانوية في مملكة البحرين وجمهورية مصر كالآتي: 1-عدم تناول وجبة الإفطار:

فقد بينت الدراسة أن •r\% من عينة الطلاب البحرينيين لا يتتاولون الفطور، وأرجع نصفهم السبب في ذللك إلى عدم وجود الوقت، وبرر ه\% مع عدم تتاول وجبة الفطور بعدم وجود

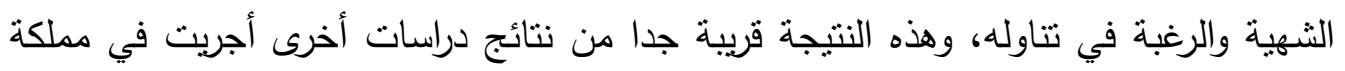

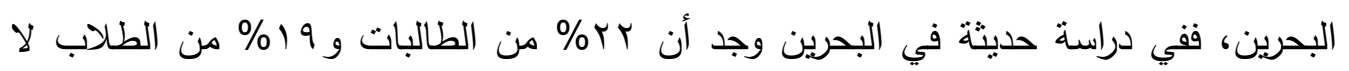

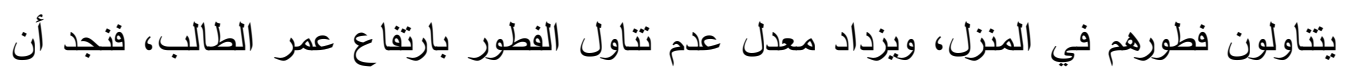

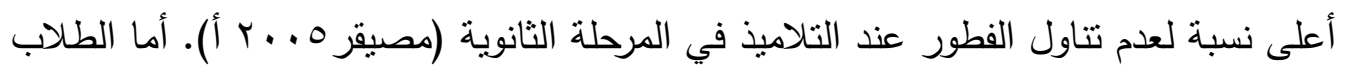
المصريون فإن هذه العادة غير منتشرة بينهم بشكل كبير، فقد بلغت نسبة من لا يتتاول وجبة الفطور منهم ع \% فقط. وهناك عدة أسباب لعدم تتاول الفطور في المنزل، وهي كالآتي:

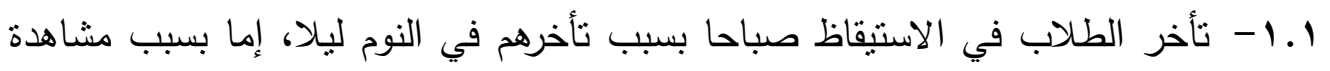

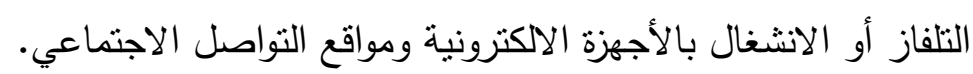
r. ا- ذهاب بعض الطلاب إلى المدارس في وقت مبكر الأمر الذي لا يمكن بعض الألت الأمهات من تحضير وجبة بسبب ضيق الوقت.

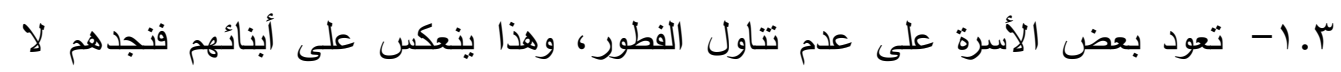
يميلون إلى تتاول الفطور كذللك. ع. ا- عدم الثعور بالجوع بعد الاستيقاظ، إما بسبب التأخر في تتاول وجبة العشاء، أو تتاول وجبة عشاء دسمة. وتعد وجبة الفطور ذات أهمية بالغة لطلاب المدارس نظرا لأنهم لا يتتاولون أطعمة مغذية

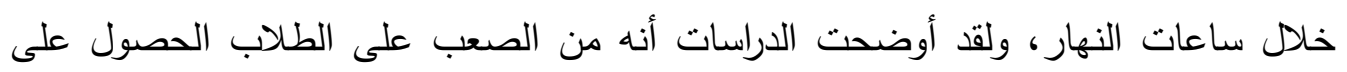
احتياجاته الغذائية اليومية بدون وجبة الفطور بسرعة الإحساس بالتعب وقلة الرغبة في العمل

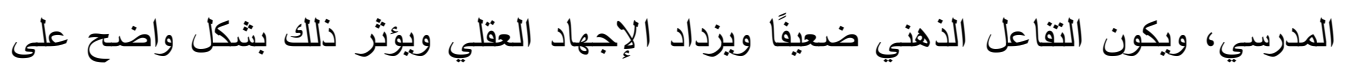

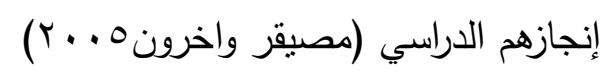

وتتشير (زينب محمد عبد الصمد r ب19 ام) إلى أن إهمال تتاول الإفطار بصورة منتظمة

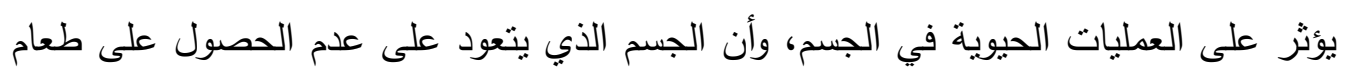

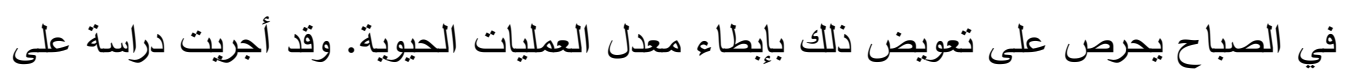


طلاب الجامعة أثنتت أن كمية المواد الدهنية والكربوهيدراتية التي كان من المفروض تتاولها في الإفطار يتم تعويضها على مدار الأربع والعشرين ساعة، بل ازدادت الكمية التي يتناولها الثخص الذي لا يفطر بمقار ، (\% عن الثخص الذي يحرص على تتاول ثلاث وجبات منتظمة. r - تناول الحلويات بين الوجبات:

من خلال الجدول السابق يظهر جليا انتشار عادة تتاول الحلويات بين الوجبات في صفوف طلاب العينيتين، فقد بلغت نسبة من يعتاد من الطلاب البحرينيين تتاول الحلويات بين

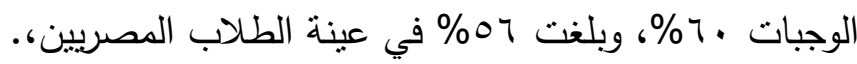

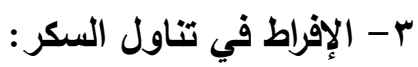

كثفت الدراسة الحالية أن نسبة كبيرة من الطلاب تفضل إضافة كمبة زائدة من السكر إلى المشروبات، فنسبة هo \% من عينة الطلبة المصريين تفضل إضافة ثلاث ملاعق للمشروبات،

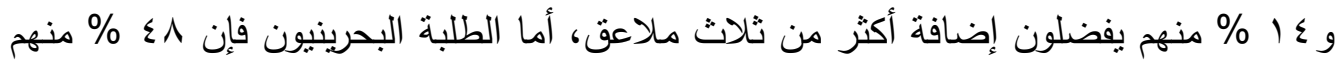
يفضلون إضافة ثلاث ملاعق للمشروبات، و 17 \% بضيفون أكثر من ذللك، وتعتبر هذه

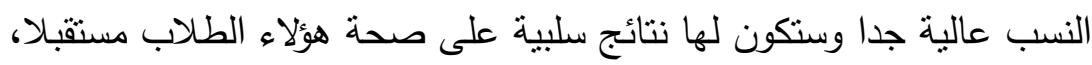

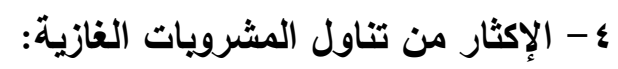

أصبحت المشروبات الغازية جزءاً مهماً من مائدة الغذاء عند العديد من الأسر، كما الأهاء

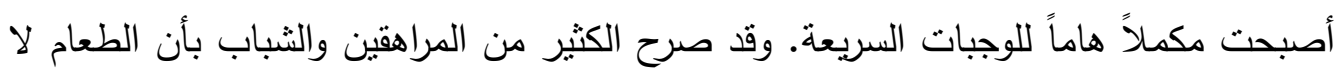

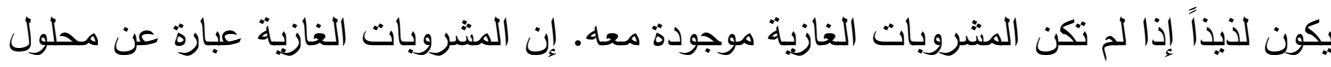

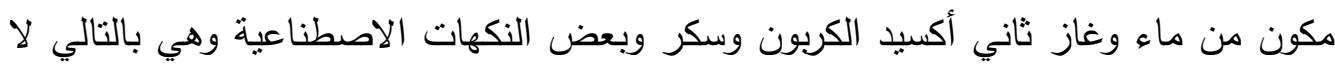
توفر أية عناصر غذائية تذكر بخلاف الطاقة الحرارية الناتجة من السكريات. فقد أوضحت ولتهن

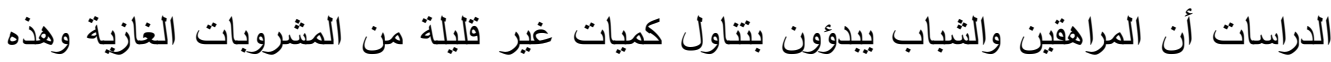
تلقائياً تحل محل العصبر مع الطعام وشرب الحليب بين الوجبات الرئيسة أو مع وجبة العشاء. فامتلاء المعدة بالمشروب الغازي يعني عدم وجود مكان لمشروبات أخرى. كما أن وجود

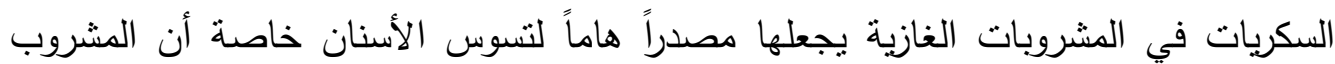
الغازي يتوزع ويتغلغل بين الأسنان، ولكن في حالة غسل الفم والمضمضة الجيدة بعد تتاول لهابل

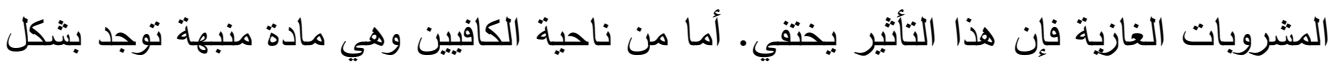

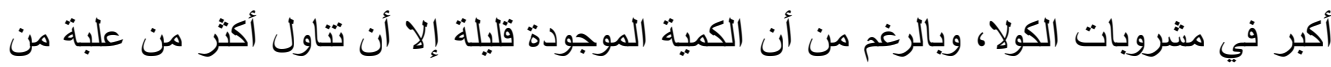


الكولا يومياً مع تتاول الثاي والقهوة يزيد من نسبة الكافيين المتتاولة يومياً أي أن مشروبات الكولا قد تكون عاملاً مساعداً في زيادة تتاول الكافيين. وبالرغم من أنه يفضل أن يعطى الأطفال والمراهقون عصائر الفاكهة والحليب المطعم

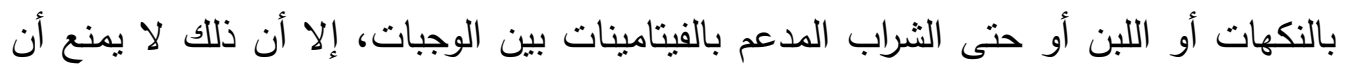

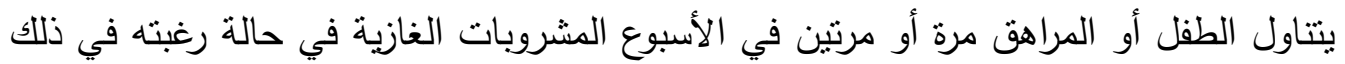
أو في حالة تأثره بالأصدقاء والجو المحيط به ومحاولة محاكاة هؤلاء الأصدقاء، ويمكن أن يتم

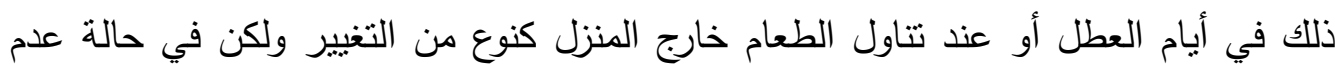

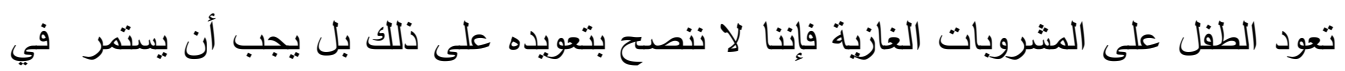

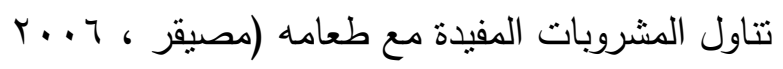
تعتبر المشروبات الغازية من الأطعمة التي لها شعبية كبيرة عند طلبة المدارس والمراهقين، وقد تعوَّد بعضهم على تتاول هذه المشروبات مع وجبة الغذاء والعشاء، فقد كثفت الته

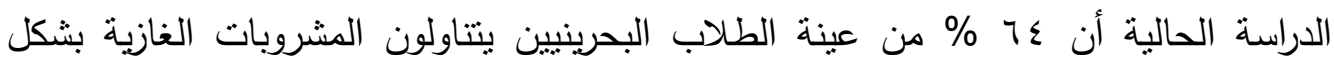

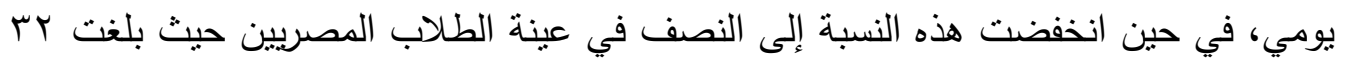

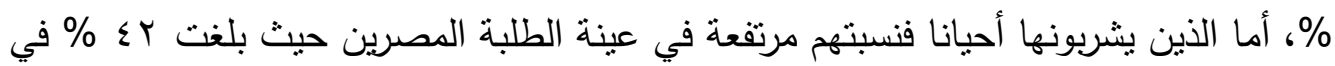

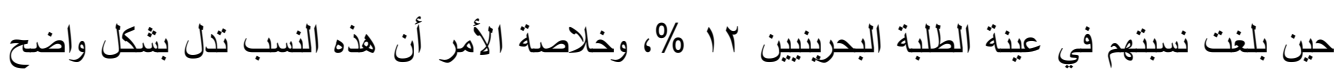
على انتتار هذه العادة في صفوف الطلبة، والتي لها أضرار خطيرة على صحتهم أهمها: ع. 1 - السمنة:

تحتوي المشروبات الغازية على كميات كبيرة من السكر حيث يشكل مع كمية السكر المضافة للبكويت والحلويات والمتلجات من العوامل المؤدية لحدوث البدانة، فقد أظهرت

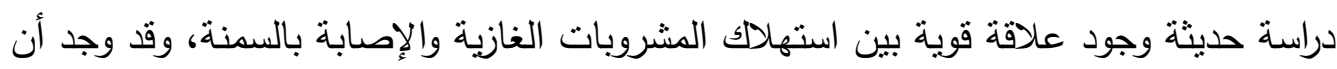

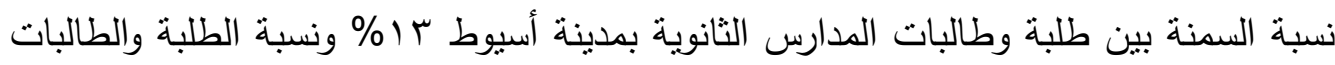

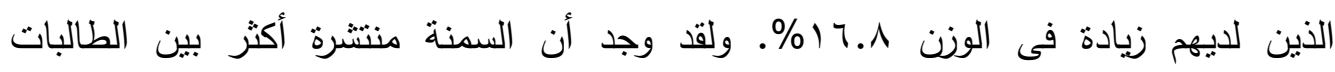

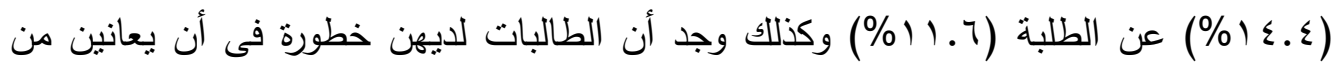

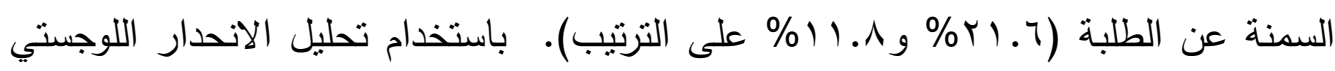

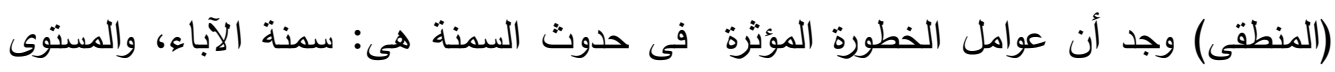

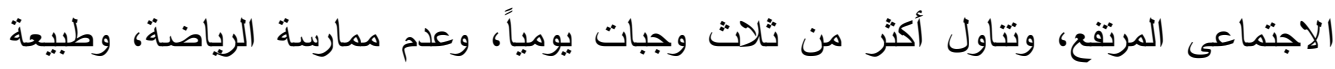
التكوين الأنثوى وبعض العادات الغذائية غير الصحية مثل: عدم تناول وجبة الإفطار والأكل 
بين الوجبات، وإنهاء الوجبات بعد الثعور التام بالثبع والامتلاء) إيمان مرسى محمد و اخرون

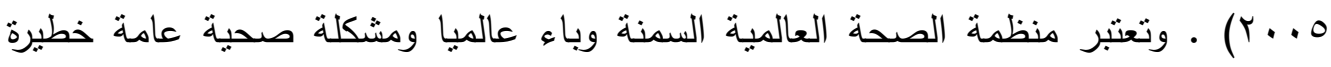

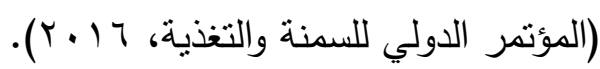

ه- ت تناول الطعام أثناء مشاهدة التلفزيون:

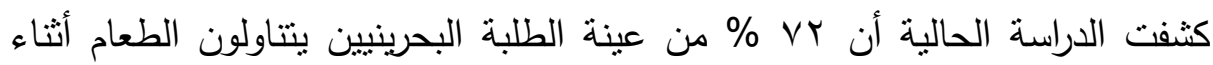

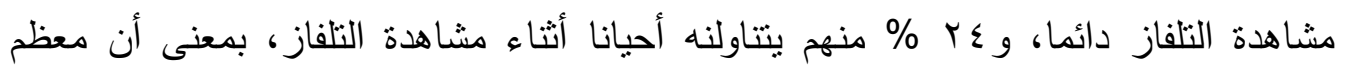

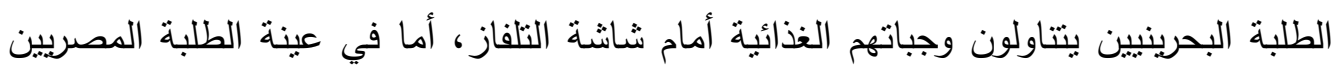
فإن النتيجة كانت على النصف من نتيجة عينة الطلبة البحرينيين، فقد كثنف الدراسة أن نسبة فئه

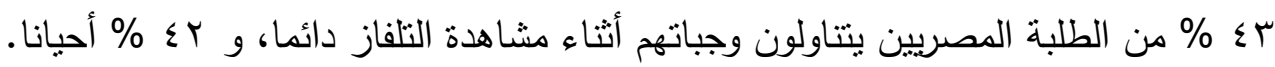
وعموما فالمسألة تعتبر ظاهرة في صفوف الطلبة، وقد أثنتت الدراسة خطورة هذا الأمر

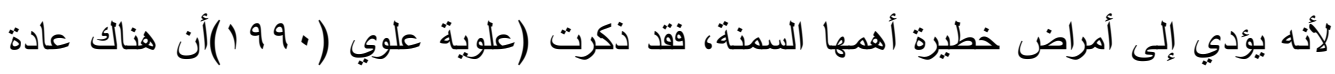

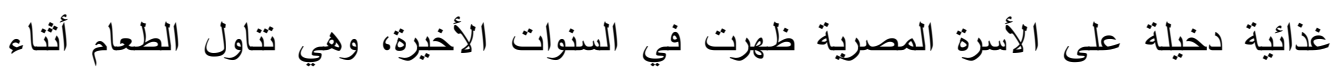

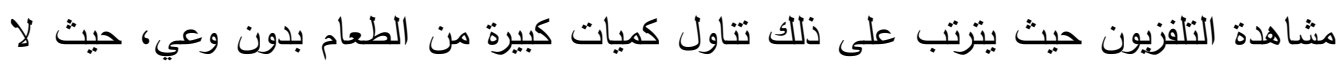
يشعر الفرد بالثبع، مما يؤدي إلى زيادة وزن الجسم والإصابة بالسمنة. צ- تناول أطعمة فقيرة في القيمة الغذائية بين الوجبات:

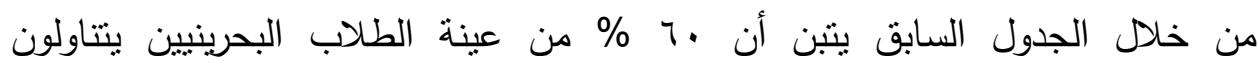
البطاطس المقلية بشكل يومي بين الوجبات الرئيسية، و ^ م \% منهم يتتاولونها أحيانا، واعتمادا

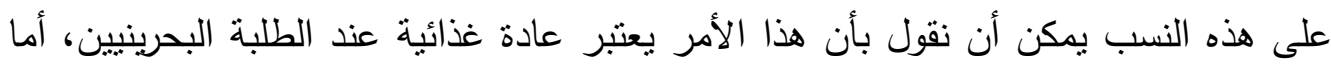

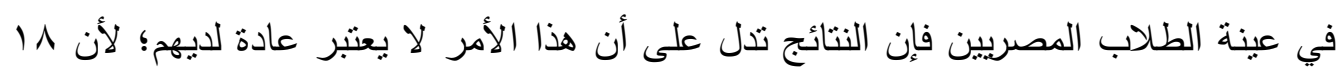

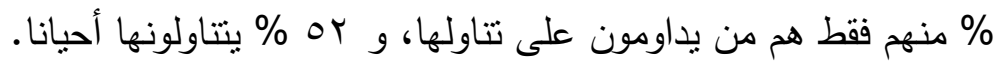

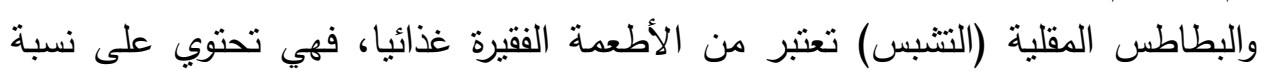

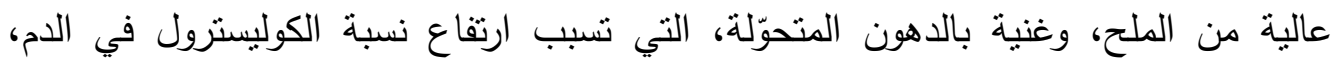

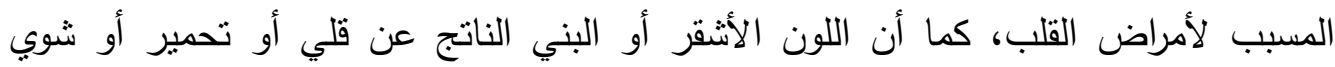

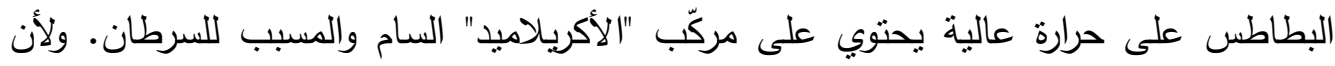

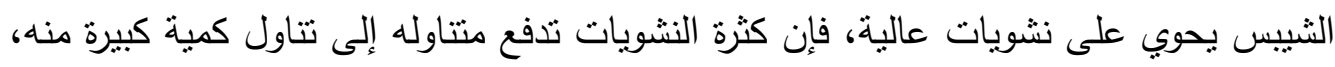
مما يؤدي إلى ابتعادهم عن تتاول الأغذية الأخرى الطبيعية ذات التهات الفائدة.

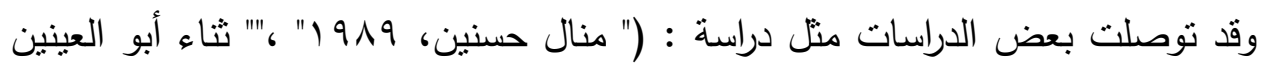

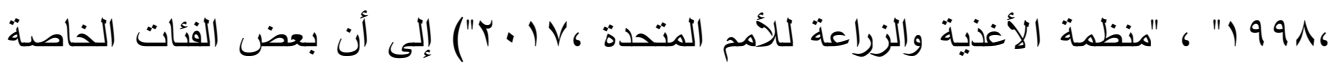
،مثل الأطفال والحوامل ومحدودي الدخل ،لا تحصل على احتياجاتها من العناصر لإنه الغذائية 
وذللك نتيجة انخفاض مستوى الوعي الغذائي لليهم الذي ينتج عنه سوء اختيار الفرد لطعامه

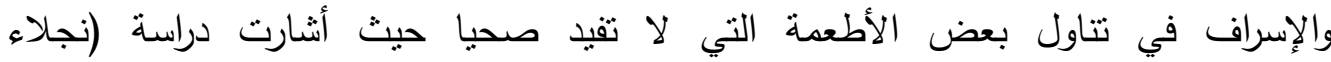

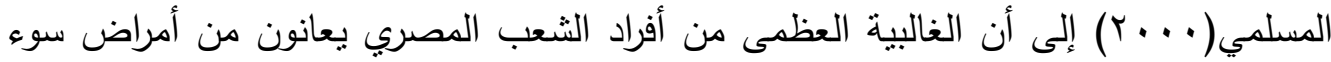

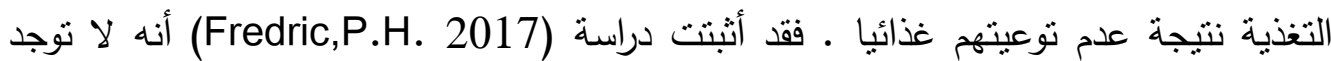
برامج في الثقافة الغذائية محددة وواضحة في بلدان العالم الثالث ،لذلك فقد أوصت الدابهة بضرورة العمل على نشر التقافة الغذائية بين الأفراد

\section{سابعا: اقتراحات وتوصيات الاراسة:}

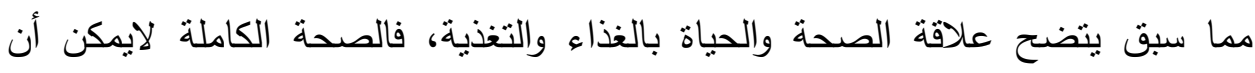

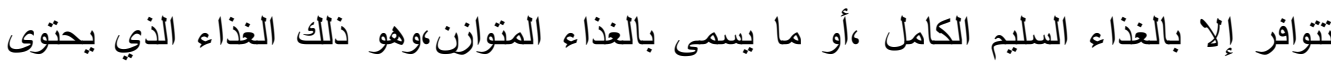

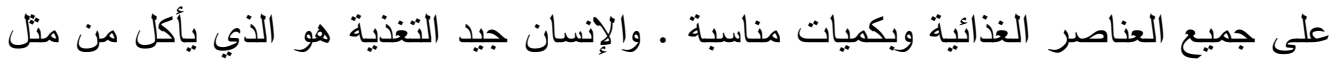

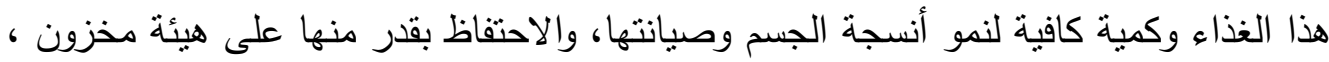
وبالتالي يكون صحيح الجسم . بما أن كل عادة تختلف عن الأخرى من حيث الأسباب والنتائج فإن الاقتراحات والحلول ستكون مقسمة وفق التقسيم السابق للعادات الغذائية.

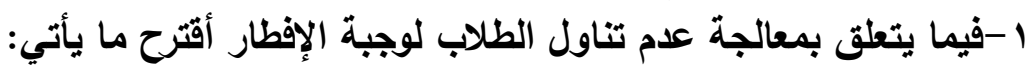

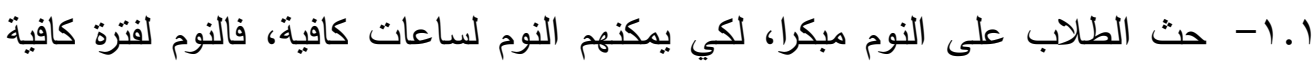

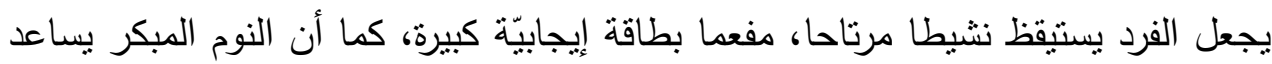

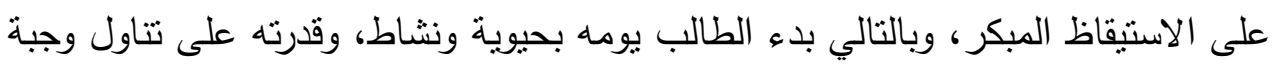

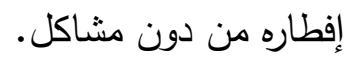

r. ا- تقنين استعمال الطلاب للأجهزة الإكترونية بالليل ومشاهدة التلفاز ، فيفضل سحبها

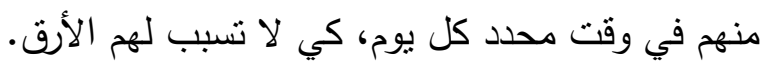

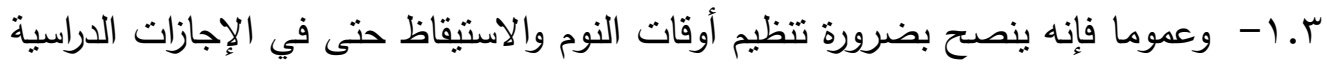
ليتدرب الطالب على النوم والاستيقاظ في مواعيد محددة.

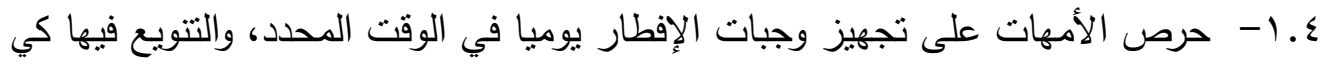

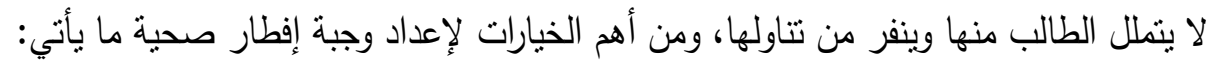

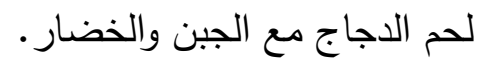
زبدة الفول السوداني، فهي مصدر غني للبروتين.

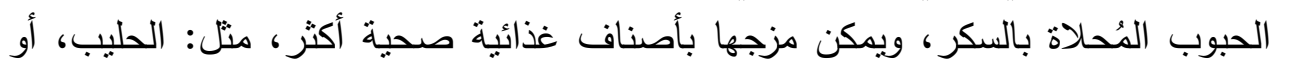
عصبر البرتقال الطازج. ه منتجات الألبان والبيض، وينبغي تقديمها بالطريقة المحببة للشخص. • الفواكه والخضراوات الطازجة. 
• الابتعاد قدر الإمكان عن اللحوم والأغذية المعالجة والمُعلبة.

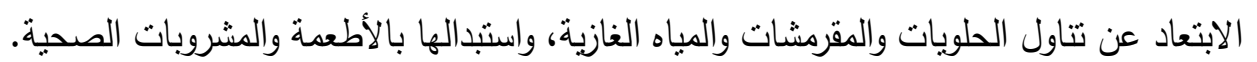

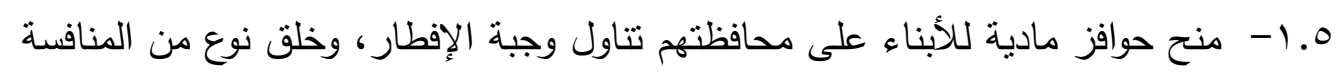
بينهم في ذلك.

1. ا- تنظيم حملات نوعوية في المدارس لتوضيح أهمية وجبة الإفطار، عن طريق نشر أنراء مطويات أو عرض أفلام، أو دعوة أطباء لتوضيح فوائد هذه الوجية. r-تناول الحلويات بين الوجبات:

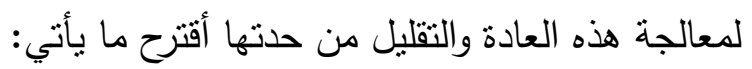

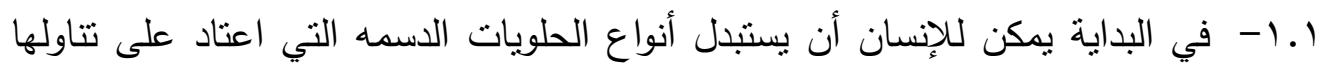

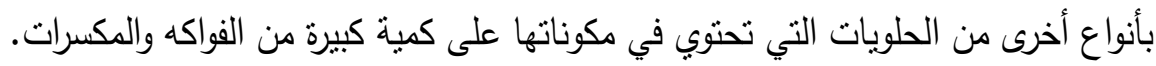

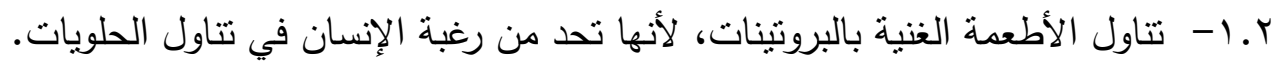

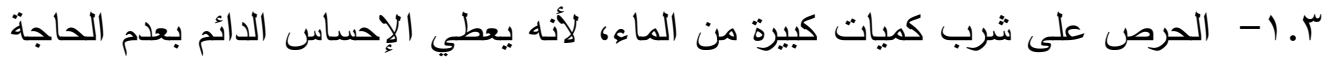
إلى أكل الحلويات والسكريات.

ـ. ا- التقليل من شرائها ووضعها في البيت بشكل تدريجي إلى أن يتم التخلص من إدمانها.

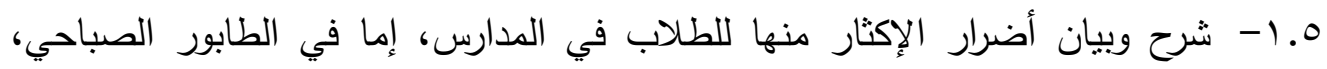

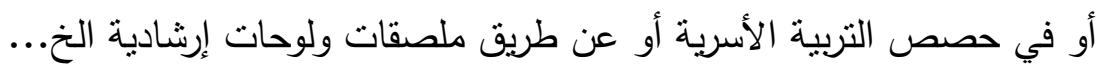

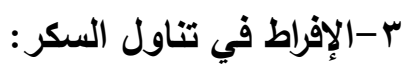
لمعالجة هذه العادة يجب: r. ا- تعوبد الطفل على التقليل من نسبة السكر المضاف إلى المشروبات بشكل تدريجي، وأن يكون ذلك تحت إثراف ومراقبة الوالدين. r.r- تعريف الطفل بأن كثيرا من العصائر الطبيعية لا تحتاج إلى تحلية لاحتوائها على فواكه حلوة طبيعيا.

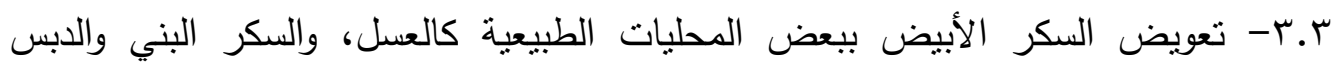

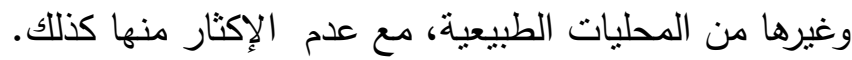

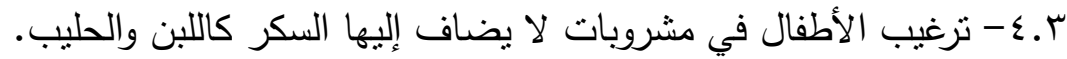

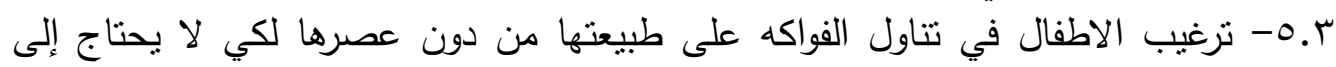
إضافة السكر إليها.

ع - الإكثار من تناول المشرويات الغازية:

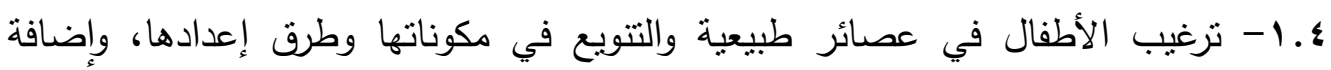
بعض البر المكسرات إليها.

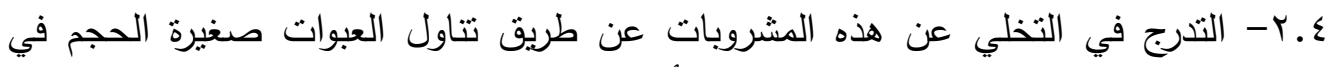

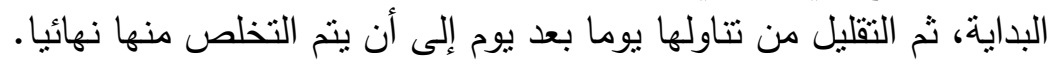


؟.ب- وضع ملصقات نوضح أضرار هذه المشروبات في المطبخ وصالة المعيشة وحتى في غرف نوم الأطفال لتخويفهم من منها. ؟.ء - تحفيز الأطفال على ترك شرب هذه الفي المشروبات عن طريق منحهم ثمن هذه المشروبات

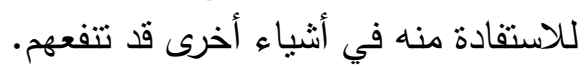

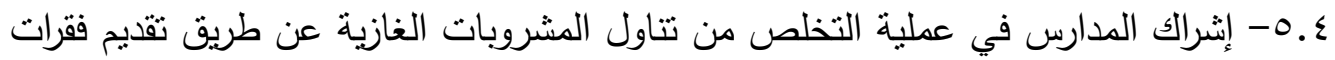

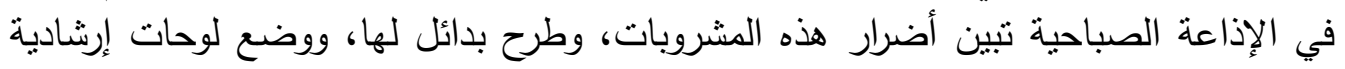

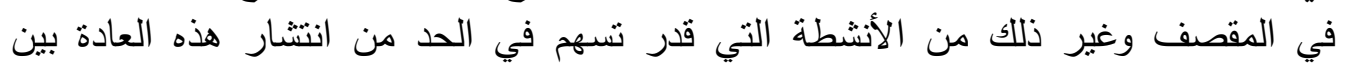

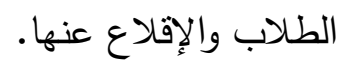
ه-تناول الطعام أثناء مشاهدة التهاء التلفزيون:

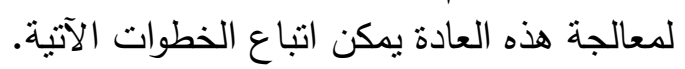

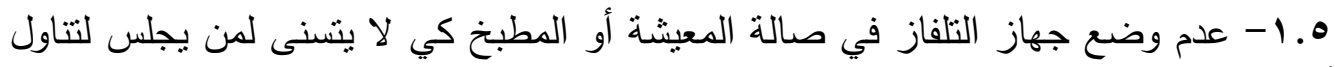
أكله مشاهدته. ه.r- طرح بعض المسائل والأمور والحديث عنها أثناء تتاول الوجبات الغذائية.

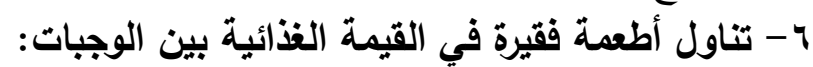

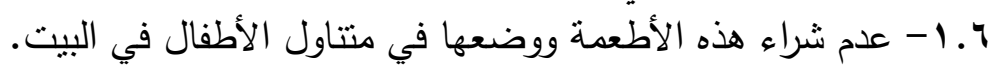

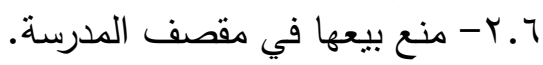

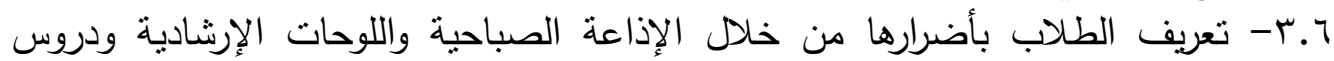

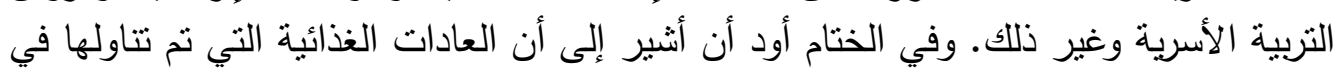

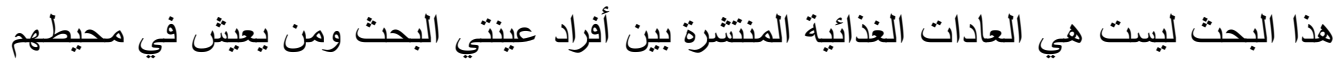

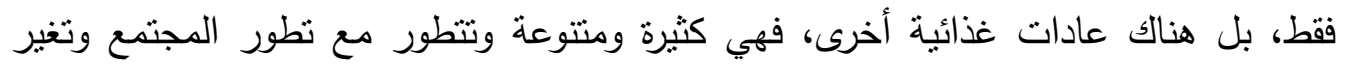

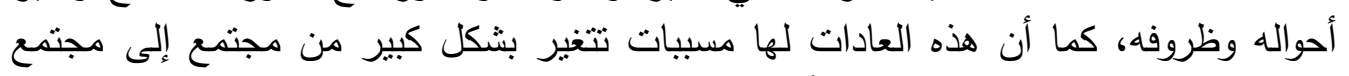

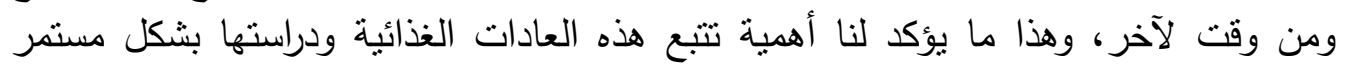
وتقديم الحلول والاقتراحات المناسبة لعلاجها. 


\section{الملحق: الاستمارة رقم (1 - ( ).}

جامعة السادات

معهد الدراسات و البحوث البادات البيئية "دراسة مقارنة للعوامل المؤثرة في العادات الغذائية بين طلاب المدارس في المرحلة الثانوية في مملكة البحرين و جمهورية مصر العربية". استمارة العادات الغذائية

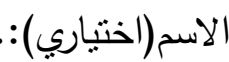

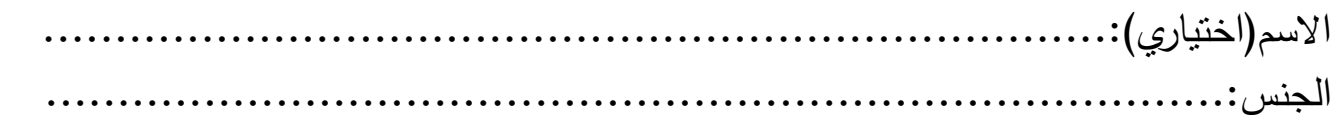
السن:...

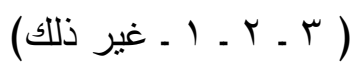

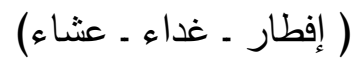

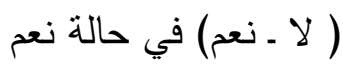

( في المنزل - في المدرسة - في الخارج )

( كاملة - جزء منها )
ا - ما هي عدد الوجبات المتتاولة في اليوج؟

r- ما هي الوجبة المحذوفة؟ هاع

ب- هل تتناول وجبة الإفطار؟ ع. أ أين بيتاوله ع. ז- هل تقوم باستهلاك الوجبة: في حال الإجابة بـ (لا) (عدم الإفطار ) لهابه

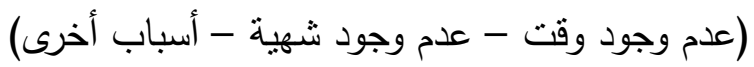
ع. ع- ما السبب

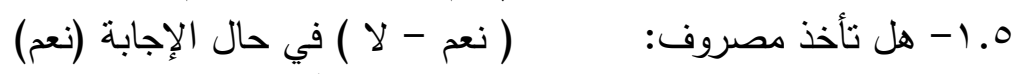

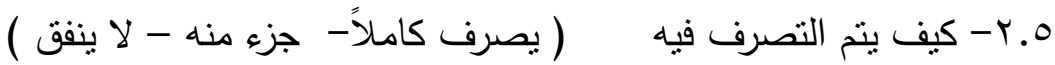
( المدرسة - خارج المدرسة ) في حال كان الثراء خارج المدرسة 0. - م- مكان الشراء

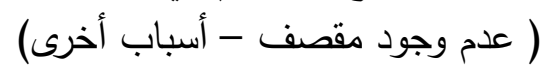

7- ما نوع الأطعمة المتتاولة بين الوجبات؟ (حلويات ـ عصائر ـ مباه غازية ـ ساندويتشات ـ فاكهة) V - كم ملعقة سكر تضيفها إلى المشروبات ( ملعقة ـ ملعقتين ـ ب ملاعق ـ أكثر من ذللك) (نعم - لا - أحيانًا)

(نعم - لا - أحيانًا)

(قليلة جدا ـ معتلة ـ مملح)

(نعم - لا - أحيانًا)

(نعم - لا - أحيانًا) - لانان)

(نعم - لا - أحيانًا) - لانان)

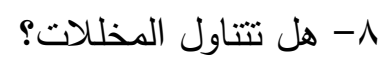
9- هل تحرص على تتاول الشاب بعد الوجبات؟ • 1 - تفضل كمية الملح في الطعام 1) - (1) هل نشرب اللبن؟ ب ا - هل تحب تتاول المياه الغازية؟

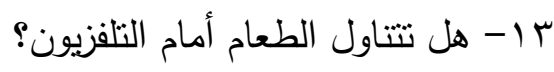
ع ا - هل تتناول البطاطس الثيبسي باعتبارها أغذية خفيفة بين الوجبات؟ (نعم ـ لا ـ أحيانًا) 


\section{المراجع العربية}

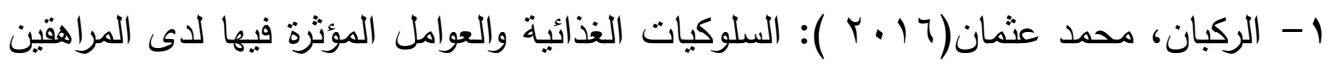

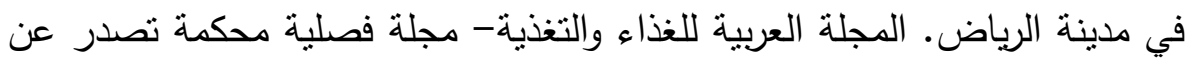

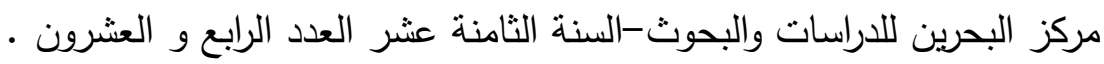

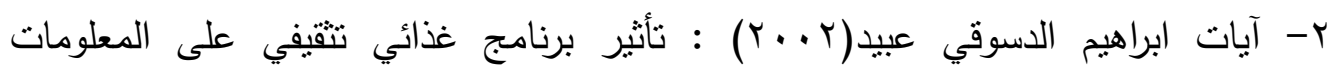

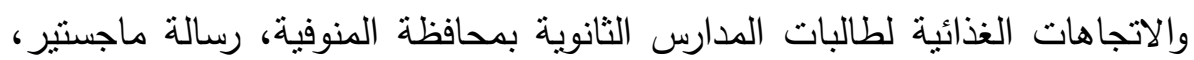

$$
\text { كلية الاقتصاد المنزلي، جامعة المنوفية }
$$

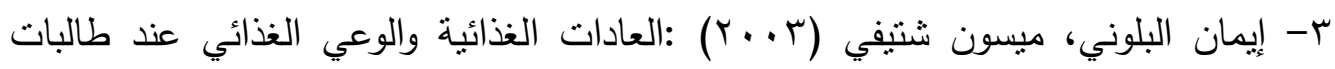

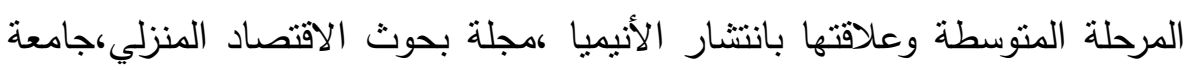

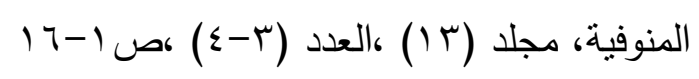

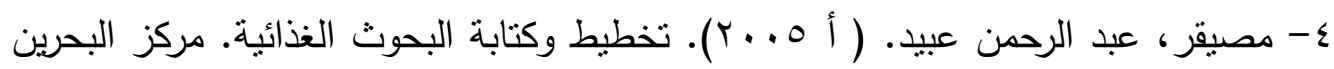

$$
\text { للاراسات والبحوث. مملكة البحرين }
$$

ه- مصيقر، عبد الرحمن عبيد، عجلان، دانة ، العوضي، زينب، خليل، سارة، العباسي، فاتن،

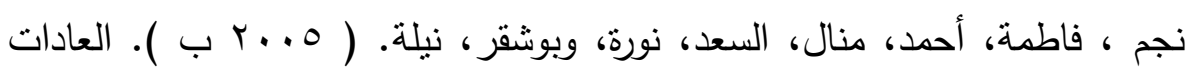
الغذائية ونمط المعيشة والأمراض المزمنة عند المواطنين البالغين في مملكة البحرين

$$
\text { (دراسة ميدانية). مركز البحرين للاراسات والبحوث. مملكة البحرين. }
$$

צ- زينب محمد عبد الصمد دراسة أنماط سلوك بعض الأسر عند استدامها لمواردها فى إعداد لادرات

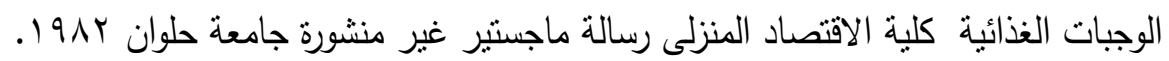

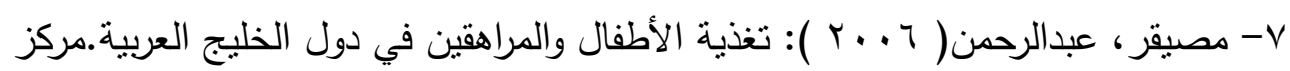

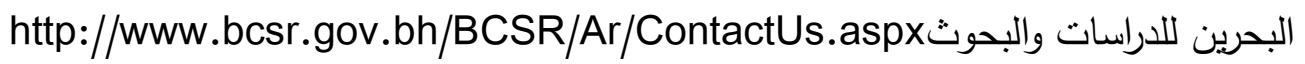
^- إيمان مرسى محمد، أحمد محمد حانى، محيى الدين عبد الرحيم سليم، مدحت عربى خليل

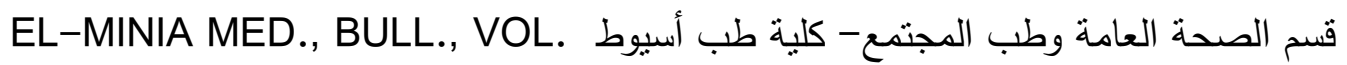

16, NO. 1, JAN., 2005-

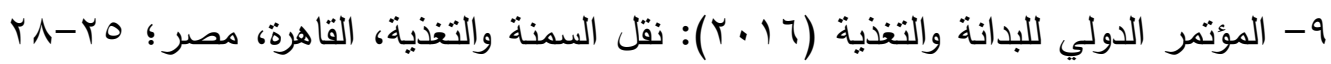

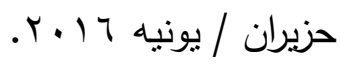


(1- علوية علوي (• 99 ()): أهمية التغذية السليمة للأسرة مع التركيز على الأم والطفل، مجلة

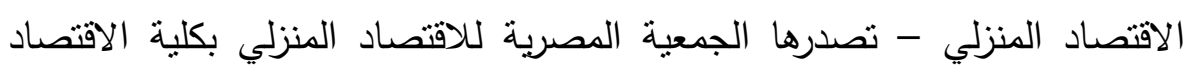

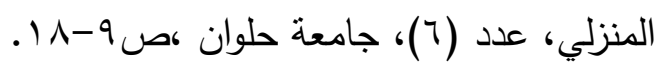

r ا ـ دراسة منال عبد الرحمن محمود حسنين( 919 (1) : مدى انتشار سوء التغذية بين الأطفال

المصابين بالطفيليات المعوية ،رسالة دكتوراه ،كلية الاقتصاد المنزلي، جامعة المنوفية .

ب ا. دراسة ثناء عبد الرحيم أبو العينين إبراهيم (991 (1): العوامل المؤثرة على سوء التغذية بين أطفال

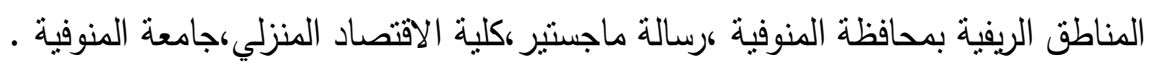

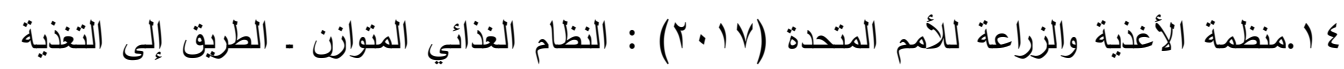

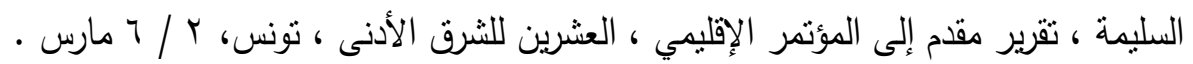

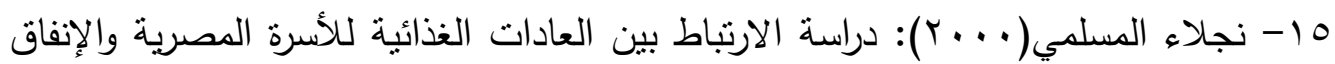

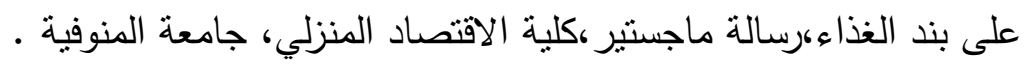

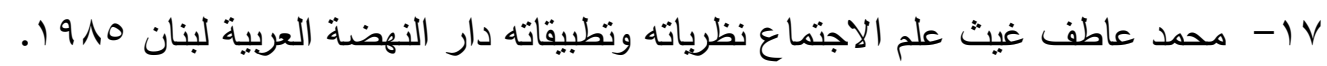

1- Ludwig, D.; Peterson, K. and Gortmaker, S. (2001): Relation between consumption of sugar-sweet-ened drinks and childhood obesity. Lancet; 357: 505-508.

2- Fredric,P.H.(2017): Saudi Medical Journal, Food and Nutrition. 